\title{
La memoria impresa: tradición del pensamiento afrodiaspórico en Colombia
}

\author{
Carlos A. Valderrama* \\ Universidad Icesi (Cali, Colombia)
}

Caicedo-Ortiz, José Antonio (2013). A mano alzada... memoria escrita de la diáspora intelectual afrocolombiana. Popayán: Sentipensar, $554 \mathrm{pp}$.

A mano alzada... memoria escrita de la diáspora intelectual afrocolombiana es un trabajo impresionante que dedica sus páginas al tema de la intelectualidad afrodiaspórica en Colombia. Es un libro de formato pequeño, pero extenso en páginas. Sin embargo, es accesible a cualquier tipo de lector. Es un libro de corte histórico, social y político, es decir, es multidisciplinario, y hace contribuciones a la sociología e historia del pensamiento social y político afrodiaspórico. En este sentido, el estudio busca mostrar las continuidades de las luchas sociales y políticas en el pensamiento social afrodiaspórico. Así lo expone el autor:

A mano alzada... memoria escrita de la diáspora intelectual a frocolombiana pretende ser una obra de convergencia entre la historia y la memoria de las luchas de intelectuales negros, afrodescendientes y afrocolombianos, protagonistas de una larga disputa epistémica, desde la cual se fue configurando un campo de saber que inicia con las denuncias tempranas de africanos en tierras del exilio en contra de la esclavitud en el siglo XVIII, el fortalecimiento comunitario, la inclusión y el reconocimiento en el siglo XX. (48)

\footnotetext{
* Doctor y magíster en Sociología por la Universidad de Massachusetts, Amherst (Estados Unidos), con una especialización en Estudios Afrodiaspóricos y Latinos de la misma universidad. Trabajador social de la Universidad del Valle (Colombia). Investigador asociado al Centro de Estudios Afrodiaspóricos (CEAF) de la Universidad Icesi (Colombia). Correo electrónico: carlos.valderrama1@correo.icesi.edu.co ORCID: https://orcid.org/oooo-ooo1-8838-8350
} 
Es claro que, para su autor, el pensamiento afrodiaspórico reúne dos dimensiones fundamentales para su desarrollo y comprensión: el ejercicio de la reflexión escrita y la acción política que proyecta en sus contenidos y productos, dimensiones intelectuales que, como sabemos, hacen parte del pensamiento radical (Bogues, 2003) y crítico (Valderrama, 2018). Así, nos recuerda que las luchas sociales y políticas de las comunidades negras en la diáspora africana no han sido exclusivas del campo de disputa y confrontación bélica o física; el pensamiento filosófico e intelectual expresado en las artes, la música, la literatura, el teatro, las ciencias sociales, la estética $\mathrm{y}$, entre otras, en la política del folclore negro han sido escenarios en los que se han desarrollado batallas culturales (Immanuel Wallerstein) o guerras de representación (Stuart Hall) por la dignificación y humanización de la gente negra en la diáspora:

El pensamiento diaspórico representa el legado de hombres y mujeres afrodescendientes, que enunciaron la realidad histórica de la esclavitud en cantos de dolor y esperanza, dejándonos sus lamentos, tonadas y voces elocuentes en la palabra impresa. Se trata de seres que hicieron de la cruda realidad una metáfora sonora, melancólica y alegre para sublimar el dolor con la poesía, el verso, la novela, los discursos políticos y la investigación social. (32)

El pensamiento afrodiaspórico debe entenderse como un proyecto humanista que refleja la voluntad de vida (Valencia-Angulo, 2019) por la dignificación del ser humano africano y sus descendientes.

El libro es prologado por dos figuras intelectuales de talla internacional, Santiago Arboleda-Quiñónez y Laurence Prescott. Se estructuró en ocho capítulos divididos en dos grandes áreas de reflexión e investigación: una teórico-conceptual y la otra de análisis empírico. En la introducción, el lector encontrará argumentos centrales, estrategia metodológica y una primera aproximación conceptual sobre el pensamiento afrodiaspórico. De la introducción, recomiendo al lector prestar mucha atención a la reconceptualización y ampliación del concepto de invisibilidad propuesto por Nina S. de Friedemann. Por otro lado, el libro tiene como propósito principal demostrar la existencia de una tradición intelectual afrocolombiana. Tradición que se puede observar en las "manifestaciones políticas, literarias, poéticas, narrativas, ensayísticas y etnológicas del pensamiento diaspórico, [y que] contienen la doble naturaleza de la diáspora, constituida en la experiencia dialéctica que lega los sometimientos y los vencimientos: memorias de sufrimientos y remembranzas libertarias" (34). La estrategia metodológica se observa rigurosa. Hay un trabajo de archivo amplio que demuestra claramente la revisión documental de libros, ensayos, discursos, textos científicos, periodísticos, revistas y documentos institucionales. Como el lector lo corroborará en su propia lectura, el análisis de contenido es exhaustivo. De este 
modo, son tres las tendencias del pensamiento afrodiaspórico en Colombia que el autor analiza. Las llama la intelectualidad parlamentaria, los humanistas y los cientistas sociales que surgieron entre la mitad del siglo XIX y finales del XX.

En los tres primeros capítulos, el autor profundiza la idea de diáspora africana, sus implicaciones empíricas y políticas para entender el pensamiento social y político afrodiaspórico. En el capitulo 1 sugiero prestar atención a conceptos o ideas como la diáspora como acontecimiento histórico (proceso, condición y proyecto de unidad y solidaridad) y que implicó la trata esclavista, el exilio, el colonialismo, el capitalismo y la explotación, trayectorias afrodescendientes de rebeldía y acciones políticas y, a su vez, los cinco rasgos característicos de la diáspora africana. Finalmente, hay una relectura crítica de las huellas de africanía. A diferencia de los críticos, la relectura que hace el autor es propositiva. Para aquellos que consideramos los puentes entre América y África fundamentales para explicar el devenir histórico de afrocolombianos, la propuesta del autor nos provee de algunos insumos para pensar las huellas de africanía en la actualidad.

El capítulo 2 se ocupa del surgimiento de las diferentes corrientes ideológicas en el pensamiento afrodiaspórico. Es un capítulo denso, extenso y bien logrado con respecto a los diferentes posicionamientos políticos e ideológicos que se encuentran en la diáspora africana: es lo que el autor denomina epistemologías diaspóricas, ya que: "la historia de las luchas anticoloniales [antiesclavistas y antirracistas] que produjo tantos 'esencialismos militantes', posteriormente se constituyó en objeto de teorización para académicos afrodescendientes (...)” (160). De esta forma, las epistemologías diaspóricas se pueden rastrear desde los movimientos de pensadores antiesclavistas con el etiopismo religioso (que incluyó, entre otros, el rastafarismo y el nacionalismo negro), el New Negro o Harlem Renaissance, el panafricanismo, la negritud, la desobediencia civil, los musulmanes negros, las perspectivas africanistas, entre otros. A pesar de las diferencias y disputas que se presentan entre las anteriores corrientes de pensamiento diaspórico, todas comparten una orientación contrahegemónica. Son antiesclavistas, antirracistas y anticoloniales. Dentro de este contexto, la producción de conocimiento liberador y la militancia política dio paso al surgimiento de intelectuales diaspóricos y a lo que el autor denomina como diásporas políticas.

En el capítulo 3 se encuentra la propuesta teórica del autor para describir el surgimiento histórico del pensamiento afrodiaspórico en Colombia. La manera como inicia el capítulo es muy diciente de su contenido. "Como lo he venido sosteniendo, el pensamiento diaspórico gravita esencialmente respecto a los eventos de la esclavitud, el colonialismo y el racismo, como hechos que marcan las trayectorias de los africanos en las distintas geografías del exilio" (177). Entonces, ¿cuáles son las carac- 
terísticas que definen al intelectual diaspórico en Colombia? Aquí presento algunos elementos, pero la invitación está abierta para que el lector las indague en el texto.

De acuerdo con el autor, el intelectual afrodiaspórico en Colombia habla desde una producción inscrita en la subjetividad negra de larga duración que se encuentra implicada en una dimensión política. "Representa una batalla epistémica por visibilizar los silencios, las ausencias y lo innombrado" (186). El pensamiento afrodiaspórico tiene una permanente preocupación por descolonizar (y yo agregaría desrracializar) el saber histórico construido sobre lo negro en la academia nacional colombiana. Como el mismo autor sugiere:
(...) la interpretación de la historia representa un rasgo constitutivo del pensamiento diaspórico, toda vez que es un asunto central para comprender el legado intelectual que ha dejado esta trayectoria diversa en los ámbitos políticos, epistémicos y culturales de la afrocolombianidad contemporánea. (187)

Esto, en su ejercicio, nos lleva a una desrracialización, es decir, a una resignificación epistémica de entender la realidad de las comunidades negras más allá de la mirada racializadora de Occidente. El pensamiento diaspórico implica en sí mismo las memorias africanas en América, la experiencia trágica de la esclavización y el colonialismo y las secuelas que estos acontecimientos e historia de poder racial-cultural han dejado en las mentalidades de los descendientes africanos y en el resto de la sociedad colombiana. En los capítulos 4, 5 y 6 el autor analiza en detalle los trabajos, discursos y producciones intelectuales de lo que él denomina la intelectualidad política, el humanismo diaspórico y la intelectualidad académica.

[Son los ámbitos de] la tradición escrita del pensamiento afrocolombiano que contiene textos, discursos y representaciones metaforizadas de africanía y criollismo negro, con sus modos disímiles, en los que se ciernen las experiencias esencialistas e híbridas de larga duración, expresadas en las trayectorias subjetivas de los intelectuales negros. (31)

Por último, el libro presenta las conclusiones. Aquí, el autor retoma los planteamientos propuestos y reflexiona sobre ellos. Con respecto al carácter afrodiaspórico de la intelectualidad negra colombiana, quisiera destacar la siguiente reflexión que Caicedo-Ortiz desarrolla:

Podemos reconocer en este movimiento que he denominado la intelectualidad diaspórica afrocolombiana, un acontecimiento fundante del pensamiento diaspórico en Colombia que hizo posible articular las narrativas locales y nacionales de la negritud con el pensamiento mundial diaspórico, logrando con ello, producir una mirada desde dentro que narró, describió y apalabró, sus experiencias culturales. (519) 
La intelectualidad afrocolombiana es una intelectualidad afrodiaspórica no solo porque revela el legado y las consecuencias del racismo, el colonialismo y la esclavitud en el contenido de sus producciones, sino porque también se ha inscrito y mantenido una relación físico-material y simbólica con el mundo de la diáspora africana.

No hay dudas de que A mano alzada... memoria escrita de la diáspora intelectual afrocolombiana es uno de los trabajos pioneros que lidia con la idea de intelectualidad afrocolombiana y cómo esta proporciona epistemologías subalternas. En tal sentido, proporciona la presencia de intelectuales negro-afrocolombianos, sus producciones de conocimiento y sus compromisos políticos, que no considerados por las ciencias sociales nacionales. En este orden de ideas, esta obra se puede convertir en una agenda de investigación académica que nos proporciona insumos sustantivos para indagar, por ejemplo, sobre el pensamiento de mujeres negras, los pensamientos afrodiaspóricos que se encuentran por fuera de la academia o los movimientos sociales afrocolombianos contemporáneos.

\section{Referencias}

Bogues, Anthony (2003). Black heretics, black prophets: radical political intellectuals. New York: Routledge.

Valderrama, Carlos A. (2018). El arte literario y la construcción oral del territorio. Pensamiento crítico afrocolombiano. Revista Colombiana de Antropología, 54(2), 93-117. https://doi. org $/ 10.22380 / 2539472 X .463$

Valencia-Angulo, Luis Ernesto (2019). Negro y afro. La invención de dos formas discursivas. Cali: Universidad Icesi. 